Antiplasmin $\alpha$-1-antitrypsin fibrinolysin $\alpha$-2-macroglobulin nephrotic syndrome plasminogen renal disease, chronic thromboembolism

\title{
Fibrinolytic Studies in the Nephrotic Syndrome
}

\author{
Jon I. Saheinman and E. Riahard Stiehm ${ }^{[40]}$ \\ Department of Pediatrics, University of Wisconsin Medical School, Madison, Wisconsin, USA
}

\begin{abstract}
Extract
Because of the susceptibility to thromboembolism exhibited by patients with the nephrotic syndrome, the fibrinolytic systems of 27 affected patients were studied and compared with those of 53 patients with other renal disorders; 26 normal subjects were used as controls. Three of the nephrotic patients had thromboembolic episodes. Patients with the nephrotic syndrome had markedly elevated levels of the antiplasmin, $\alpha$-2-macroglobulin (mean $1290 \mathrm{mg} / 100 \mathrm{ml}$ ), as determined by an immunological radial diffusion assay, when compared with normal controls (mean $270 \mathrm{mg} / 100 \mathrm{ml}$ ) and with other patients with chronic renal disease (mean $380 \mathrm{mg} / 100 \mathrm{ml}$ ). High levels of $\alpha$-2-macroglobulin in the serum were directly related to increased measured values of serum antiplasmin (antifibrinolysin) activity. These abnormalities persisted, to a lesser degree, during remission of idiopathic nephrotic syndrome.

Plasminogen (profibrinolysin) levels, as determined by radial diffusion, were reduced in idiopathic nephrotic syndrome (mean $62 \%$ of adult normal), including the three patients with thromboembolic episodes. Levels of $\alpha$-1-antitrypsin, a slow-acting antiplasmin, were neither altered in the nephrotic syndrome nor correlated with antiplasmin activity. Low levels of serum albumin were correlated with high $\alpha$-2-macroglobulin concentrations. Nine patients, all with the nephrotic syndrome and including the three patients with thromboembolism, had both elevated levels of $\alpha$-2-macroglobulin and antifibrinolysin activity and decreased levels of plasminogen.
\end{abstract}

\section{Speculation}

The elevated $\alpha$-2-macroglobulin level and decreased plasminogen activity in patients with the nephrotic syndrome may result in defective fibrinolysis and thromboembolic complications. Prospective studies will be necessary to determine if these measurements have predictive value in determining risk of thromboembolism. The therapy of the nephrotic syndrome should be evaluated not only for its effect on the disease, but also for its effect on the fibrinolytic system.

\section{Introduction}

Patients with the nephrotic syndrome treated with steroids are unusually susceptible to thromboembolic disease $[9,15]$. Although chronic intravascular coagulation is not regularly found in the nephrotic syndrome [27], several coagulation abnormalities have been described which suggest a hypercoagulable state with a thromboembolic potential $[2,4]$. Deficient fibrinolysis may also predispose to thromboembolism; this could be due to a deficiency of plasminogen or its activators, excessive antiactivator, or increased antiplasmin (antifibrinolysin) activity [21].

Since $\alpha$-2-macroglobulin, the major antiplasmin in serum, is markedly elevated in the nephrotic syndrome $[12,16,22,25]$, we have investigated the fibrinolytic system in patients with the nephrotic syndrome, including three patients with thromboembolic disease. 
We compared patients with idiopathic and secondary nephrotic syndrome with patients having idiopathic nephrotic syndrome in remission, with those suffering from other chronic renal disease, and with normal controls. Serum proteins related to the fibrinolytic system including $\alpha$-2-macroglobulin, $\alpha$-1-antitrypsin, plasminogen, and albumin were assayed; total antifibrinolysin activity, euglobulin clot lysis time, and caseinolytic plasminogen activity were also determined.

\section{Materials and Methods}

The study group consisted of 26 controls (20 adults, 6 children) and 53 patients with renal disease from the Pediatric and Medical Services of the Universities of Iowa and Wisconsin Medical Centers. Seventeen patients (14 children, 3 adults) had idiopathic nephrotic syndrome without hypertension, azotemia, or hematuria; in 9 of these a renal biopsy disclosed no glomerular pathology by light microscopy. Three had congenital nephrotic syndrome, with the onset of disease in the first 3 months of life.

Twelve of the nephrotic patients were studied during exacerbation or relapse; i.e., proteinuria exceeding 4.0 $\mathrm{g} / 1.73 \mathrm{~m}^{2} / 24 \mathrm{hr}$. These patients also had hypoalbuminemia, with serum albumin concentration less than 3.0 $\mathrm{g} / 100 \mathrm{ml}$, and edema, and were receiving steroids. Three had thromboembolic episodes at the time of the study and are described in detail later. Nine patients with idiopathic nephrotic syndrome were studied during remission, i.e., absence of significant proteinuria, less than $1.0 \mathrm{~g} / 1.73 \mathrm{~m}^{2} / 24 \mathrm{hr}$, edema, or hypoalbuminemia, in a patient who had previously fulfilled the criteria for idiopathic nephrotic syndrome in exacerbation. These nine patients received steroid therapy on alternate days.

Thirty-six other patients with renal disorders had hematuria, hypertension, or evidence of chronic renal disease in a renal biopsy. Ten patients in this group (seven children, three adults) had secondary nephrotic syndrome with proteinuria (over $4.0 \mathrm{~g} / 1.73 \mathrm{~m}^{2} / 24 \mathrm{hr}$ ), hypoalbuminemia, and edema. Ten other patients (three children, seven adults) had hypoalbuminemia, without significant proteinuria or edema. Sixteen patients (nine children, seven adults) with chronic renal disease had no proteinuria, hypoalbuminemia, or edema; nine of these had renal insufficiency, with blood urea nitrogen concentrations exceeding $30 \mathrm{mg} /$ $100 \mathrm{ml}$.

Blood samples were obtained from all patients and allowed to clot for 1-4 hr. The serum was separated and kept frozen at $-70^{\circ}$ or, with the addition of $0.1 \%$ sodium azide, at $-25^{\circ}$. Albumin, plasminogen, $\alpha-2$ macroglobulin, $\alpha$-1-antitrypsin, and antifibrinolysin determinations were done immediately after thawing. Plasma and serum levels of plasminogen and antifibrinolysin were not significantly different as determined by simultaneous assays on pairs of plasma and previously frozen serum samples from 10 patients. For fibrinogen, euglobulin clot lysis time, and caseinolytic plasminogen assays blood was collected in 0.1 volume of $3.8 \%$ sodium citrate, chilled immediately and assayed within 4 hr.

Levels of albumin, $\alpha$-I-antitrypsin [30], plasminogen, and $\alpha$-2-macroglobulin in serum were measured by radial diffusion utilizing monospecific rabbit antisera prepared in our laboratory. The antigens used in their preparation were crystalline human serum albumin, commercial plasminogen [31], purified $\alpha$-2-macroglobulin (prepared as described below), and an $\alpha$-1-antitrypsin-enriched fraction of plasma obtained by starch block electrophoresis and Sephadex G-200 fractionation. The pooled antisera were made monospecific by appropriate absorptions as monitored by immunoelectrophoresis.

Initial purification of $\alpha$-2-macroglobulin utilized 6,9-diamino-2-ethoxyacradine lactase monohydrate [32] precipitation as described by Steinbuch et al [24]. Further purification with Bentonite, as suggested by these authors, resulted in loss of the protein. Therefore, the preparation was concentrated 10-fold by pervaporation, dialyzed in $0.16 \mathrm{M} \mathrm{pH} 8.2$ Tris buffer, and chromatographed on a Sephadex G-200 column $(114 \mathrm{~cm}$ by $2.0 \mathrm{~cm}$ ) equilibrated with the same buffer. The first protein peak, containing $\alpha$-2-macroglobulin and traces of other proteins, was used as an antigen. Pooled antiserum to this fraction was absorbed with protein from the second and third peaks of similarly chromatographed human plasma. Approximately 35 $\mathrm{mg}$ of protein were necessary to absorb other antibodies from $10 \mathrm{ml}$ of antiserum. On immunoelectrophoresis, the absorbed antiserum gave a single precipitin line with human serum and purified $\alpha$-2-macroglobulin.

The radial immunodiffusion assays [17] for $\alpha-2$ macroglobulin, $\alpha$-1-antitrypsin, plasminogen, and albumin were standardized by assaying a reference serum in duplicate on each plate. The protein concentrations in the reference serum were determined by comparison with a commercial standard serum [35] for albumin $(3010 \mathrm{mg} / 100 \mathrm{ml})$ and $\alpha$-2-macroglobulin $(120 \mathrm{mg} / 100 \mathrm{ml})$ or with an adult serum pool assigned the values of $150 \mathrm{mg} / 100 \mathrm{ml}$ for $\alpha$-1-antitrypsin and $100 \%$ for plasminogen. Using these values, mean levels of these proteins in normal adult sera were: albumin, 
$4.23 \pm 91 \mathrm{~g} / 100 \mathrm{ml}$ [32] (20 samples); $\alpha$-1-antitrypsin, $108 \pm 16 \mathrm{mg} / 100 \mathrm{ml}$ (11 samples); plasminogen, 101 $\pm 22 \%$ (21 samples); and $\alpha$-2-macroglobulin $256 \pm 91$ $\mathrm{mg} / 100 \mathrm{ml}$ (20 samples). Concentrations of these proteins in the study were considered abnormal if deviation from the normal mean was greater than $2 \mathrm{sD}$.

Serum antifibrinolysin activity was determined by the method of Guest et al. [10, 11] based on the inhibition of lysis of a fibrin clot by activated fibrinolysin. Reagents used were bovine fibrinogen, purified to $75 \%$ clottability from Cohn Fraction I [33], and bovine chloroform-activated fibrinolysin [34]. Antifibrinolysin activity in the test serum was determined from a curve of lysis time versus concentration of dilutions of a normal control serum. For this curve, as suggested by Guest et al. [10], a time of $210 \mathrm{sec}$ was assigned the value of 5 units. The units of antifibrinolysin were multiplied by the dilution factor to give units per milliliter. The mean level of 18 normal samples was $28.8 \pm 6.5 \mathrm{U} / \mathrm{ml}(1 \mathrm{sD})$, somewhat lower than the values obtained by Guest et al. [11].

Fibrinogen was determined turbidimetrically on fresh plasma [6]; the normal range is $200-400 \mathrm{mg} / 100$ $\mathrm{ml}$. The euglobulin clot lysis time was performed on fresh plasma according to the method of Copley et al. [3]; the normal time is 2-6 hr. Caseinolytic plasminogen activity was determined by the method of Swaim [28].

Statistical analyses utilized a linear correlation coefficient $(r)$, in which values may vary from -1.00 (perfect negative correlation) to +1.00 (perfect positive correlation). The statistical significance of the $r$ values and the means in different groups of patients were assessed by Student's $t$ test. Correlations were considered significant if the null hypothesis had a probability $(P)$ of 0.05 or less. For graphic purposes, the line of least squares was drawn for certain significant correlations.

\section{Results}

\section{Albumin and Plasminogen}

Figure 1 illustrates the albumin levels in the different patient groups, as well as the levels of plasminogen, $\alpha$-2-macroglobulin, and antifibrinolysin activity. $\mathrm{Pa}$ tients with idiopathic nephrotic syndrome in remission (NS-Rem) and chronic renal disease (CRD) had normal levels of serum albumin with mean levels of 4.5 and 4.1 $\mathrm{g} / 100 \mathrm{ml}$, respectively. Patients with chronic renal disease and hypoalbuminemia (CRD $\downarrow$ Alb), chronic renal disease with nephrotic syndrome (CRD-NS), and idiopathic nephrotic syndrome in exacerbation (NSExac) had low levels of albumin, with mean levels of 2.6, 1.9 , and $1.2 \mathrm{~g} / 100 \mathrm{ml}$, respectively. Plasminogen levels paralleled those of albumin; the correlation between the values of plasminogen and albumin for all patients was significant $(r=+0.752, P<0.001)$. Patients without the nephrotic syndrome (NS-Rem, CRD, and CRD $\downarrow \mathrm{Alb}$ ) had normal levels of plasminogen; those with nephrotic syndrome secondary to chronic renal disease had depressed levels (mean $79 \%$ control), but only one of these patients was distinctly abnormal with a plasminogen level 2 so below the normal mean. All of the other eight patients with low levels of plasminogen had idiopathic nephrotic syndrome in exacerbation; the mean level of plasminogen in this group was $62 \%$ of control.

\section{$\alpha$-2-Macroglobulin and Antifibrinolysin}

Patients with idiopathic nephrotic syndrome in exacerbation and secondary nephrotic syndrome had markedly elevated levels of $\alpha$-2-macroglobulin with means of 1380 and $1190 \mathrm{mg} / 100 \mathrm{ml}$, respectively, which differed significantly from the control mean of 256 $\mathrm{mg} / 100 \mathrm{ml}$. Elevated levels of $\alpha$-2-macroglobulin with a mean of $750 \mathrm{mg} / 100 \mathrm{ml}$ persisted in patients with idiopathic nephrotic syndrome in remission, even though all signs of the disease had disappeared and albumin and plasminogen levels had returned to normal. Patients with chronic renal disease and chronic renal disease with hypoalbuminemia had less striking but significant elevations of $\alpha$-2-macroglobulin, with mean levels of 533 and $399 \mathrm{mg} / 100 \mathrm{ml}$, respectively (Fig. 1), even where variations due to age and sex were considered [8]. There was an inverse relation between $\alpha$-2-macroglobulin and albumin concentration $(r=$ $-0.905, P<0.001$ ), for all samples; this relation could not be demonstrated when $\alpha$-2-macroglobulin values were in the normal range $(r=0.136, P$ not significant).

Antifibrinolysin activity paralleled $\alpha$-2-macroglobulin concentrations; the greatest antifibrinolysin activities were found in patients with idiopathic nephrotic syndrome in exacerbation and chronic renal disease with nephrotic syndrome, with mean levels of 87 and $72 \mathrm{U} / \mathrm{ml}$, compared with the normal mean of 28.6 $\mathrm{U} / \mathrm{ml}$. Significant increases in antifibrinolysin activity were also present during remission of idiopathic nephrotic syndrome and in chronic renal disease, with means of 40.3 and $40 \mathrm{U} / \mathrm{ml}$, respectively. The correlation between antifibrinolysin activity and $\alpha$-2-macroglobulin concentration was highly significant for the 

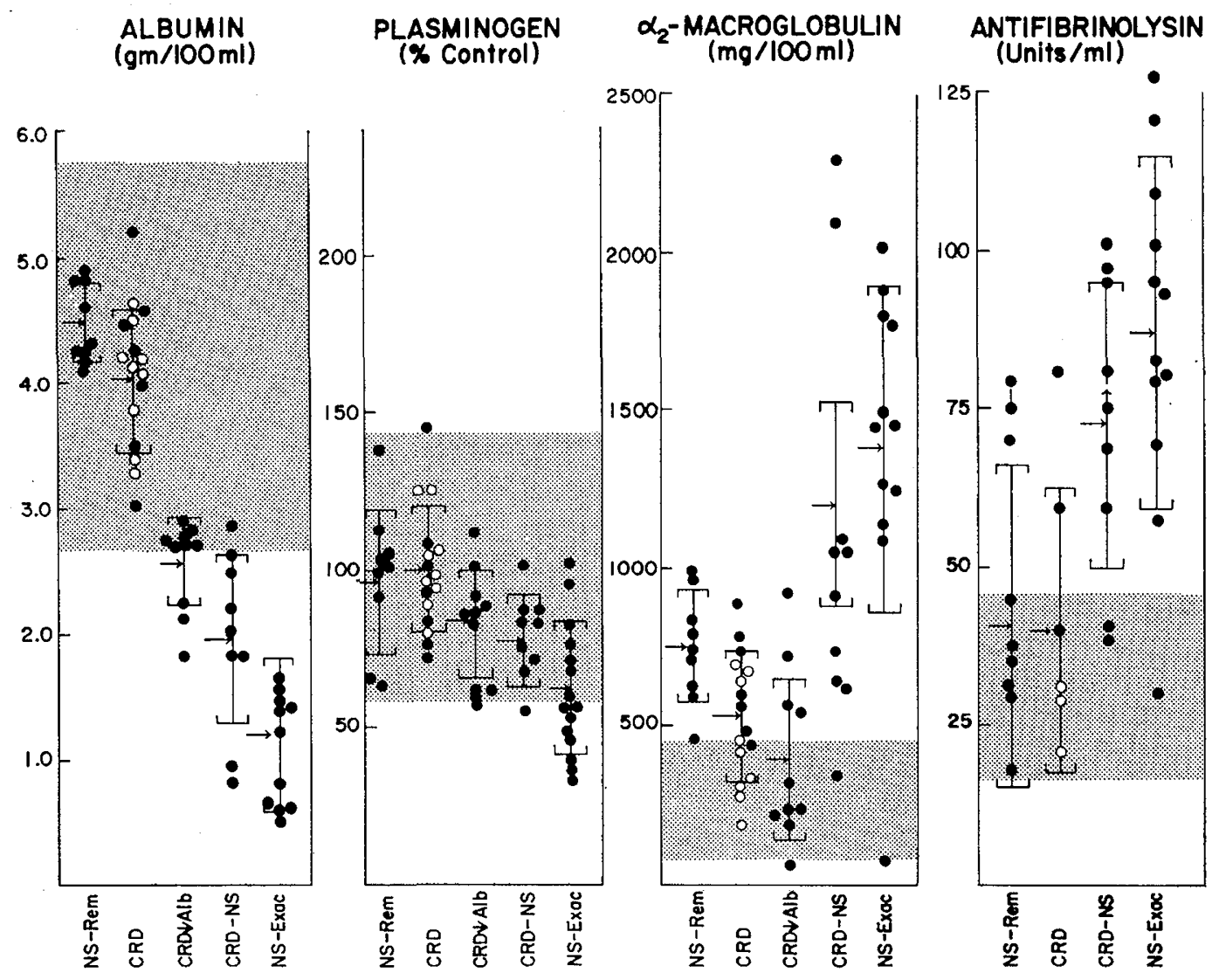

Fig. 1. Distribution of levels of albumin, plasminogen, $\alpha$-2-macroglobulin and antifibrinolysin activity in the patient groups. The normal levels (mean $\pm 2 \mathrm{sD}$ ) are shaded. The open circles in the CRD columns indicate patients with renal insufficiency. Abbreviations used are: NS-Exac, idiopathic nephrotic syndrome in exacerbation; NS-Rem, idiopathic nephrotic syndrome in remission; CRD, chronic renal disease with normal albumin and without nephrotic syndrome; CRD $\downarrow$ Alb, chronic renal disease with hypoalbuminemia but without nephrotic syndrome; CRD-NS, chronic renal disease with nephrotic syndrome.

entire patient group $(r=0.845, P<0.001)$, as illustrated in Figure 2, but not for the normal controls $(r$ $=0.240, P$ not significant).

\section{Other Studies}

$\alpha$-1-Antitrypsin levels were elevated in patients with chronic renal disease (mean level $125 \mathrm{mg} / 100 \mathrm{ml}$ in CRD, $160 \mathrm{mg} / 100 \mathrm{ml}$ in CRD $\downarrow$ Alb and $135 \mathrm{mg} / 100$ $\mathrm{ml}$ in CRD-NS), compared with the normal mean of $108 \mathrm{mg} / 100 \mathrm{ml}$. The $\alpha$-1-antitrypsin levels were decreased in patients with idiopathic nephrotic syndrome, in exacerbation (mean $74 \mathrm{mg} / 100 \mathrm{ml}$ ) and remission (mean $78 \mathrm{mg} / 100 \mathrm{ml}$ ). When all patients were included, there was no correlation between $\alpha$-l-antitrypsin concentration and antifibrinolysin activity $(r$ $=-0.181, P$ not significant $)$.

The euglobulin clot lysis times in 7 of 11 patients with idiopathic nephrotic syndrome in exacerbation and chronic renal disease with nephrotic syndrome were prolonged for greater than $6 \mathrm{hr}$. Euglobulin clot lysis times, however, were related to the elevated fibrinogen (substrate) concentrations in the $32 \mathrm{pa}$ tients studied $(r=0.747, P<.001)$. Mean fibrinogen levels for chronic renal disease were $480 \mathrm{mg} / 100 \mathrm{ml}$; for chronic renal disease with hypoalbuminemia were $600 \mathrm{mg} / 100 \mathrm{ml}$; for chronic renal disease with nephrotic syndrome were $860 \mathrm{mg} / 100 \mathrm{ml}$; and for idiopathic nephrotic syndrome in exacerbation were $590 \mathrm{mg} / 100 \mathrm{ml}$ (only four patients).

Caseinolytic plasminogen activity was determined on 24 plasma samples for which the corresponding sera were assayed by the immunochemical plasminogen method. As found by Rabiner et al. [23], the results of the two methods were poorly correlated $(r=0.379, P$ $<0.10)$.

Nine patients had the combined abnormalities of 


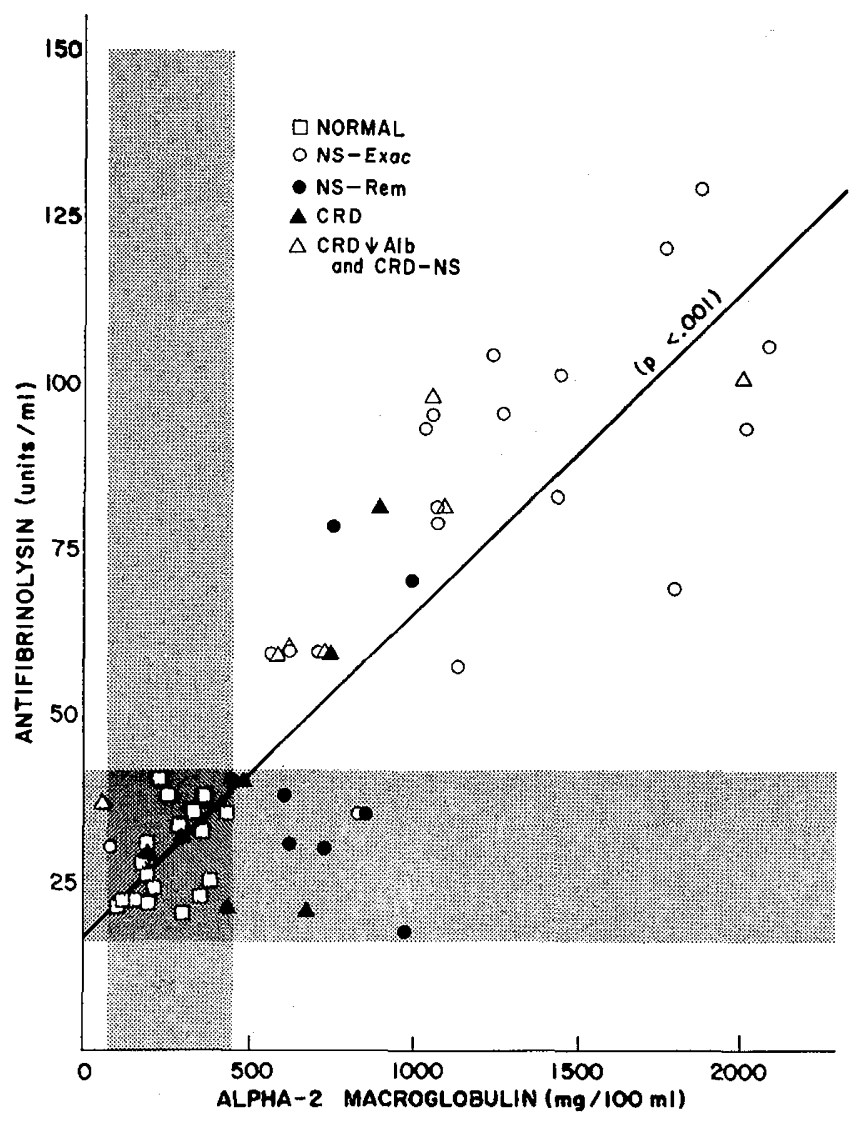

Fig. 2. Scattergram of levels of $\alpha$-2-macroglobulin versus antifibrinolysin activity. The shaded areas indicate the normal ranges (mean $\pm 2 \mathrm{sD}$ ). The line of least squares is drawn for the relation between $\alpha$-2-macroglobulin levels and antifibrinolysin activity, and the probability for this relation $(P)$ is indicated. Abbreviations used are defined in Figure 1.

low levels of albumin and plasminogen and high levels of $\alpha$-2-macroglobulin or antifibrinolysin activity; eight had idiopathic nephrotic syndrome in exacerbation and one had nephrotic syndrome secondary to chronic renal disease. All were receiving therapy with steroids. Three of these patients had thromboembolic episodes; these included a 12-year-old boy with femoral vein thrombosis following femoral venipuncture, a 3-yearold girl with cerebrovascular thrombosis, and a 7-yearold girl with peripheral thrombophlebitis and the onset of chronic glomerulonephritis.

\section{Discussion}

The abnormalities found in the nephrotic syndrome, including elevated levels of $\alpha$-2-macroglobulin, increased antifibrinolysin (antiplasmin) activity, decreased levels of plasminogen, and prolonged euglob- ulin clot lysis times, suggest sluggish fibrinolysis. As measured by these criteria, patients with nephrotic syndrome secondary to chronic renal disease were less severely affected than patients with idiopathic nephrotic syndrome; these latter patients had persistent abnormalities even during periods of remission. In both groups of patients with active nephrotic syndrome the results of fibrinolytic studies differed significantly from those of normal controls and of those from patients with other forms of renal disease including those with low albumin levels.

The immunological procedures used confirm previous observations of high $\alpha$-2-macroglobulin (by ultracentrifugal techniques) $[12,25]$ and low plasminogen (by caseinolytic technique) [5] in the nephrotic syndrome. As noted by others [12, 13, 19], levels of $\alpha-2$ macroglobulin, but not $\alpha$-1-antitrypsin, are related to plasma or serum antifibrinolysin activity. Prolonged euglobulin clot lysis times in the nephrotic syndrome as noted in this and other studies [5] may reflect a true decrease in fibrinolytic activator; however, the increased substrate (fibrinogen) or plasmin inhibitor $(\alpha-2$ macroglobulin) in the euglobulin clot could also cause a prolonged lysis time.

The mechanisms by which fibrinolytic abnormalities are produced in the nephrotic syndrome are not clear but seem to be related to the hypoalbuminemia. The low levels of plasminogen may result from increased urinary loss [26], but increased consumption [13] cannot be excluded. The high levels of $\alpha$-2-macroglobulin in nephrotic subjects may in part be due to a slightly prolonged survival [14]. This is an inadequate explanation for the marked elevations noted so that increased synthesis of $\alpha$-2-macroglobulin also must occur.

The association of plasma fibrinolytic abnormalities with thromboembolic disease is not limited to patients with the nephrotic syndrome. Naeye [18] reported two previously well patients in whom thromboembolic episodes during infections were associated with an increase in antifibrinolytic activity. Nillson et al. [20] reported a man with elevated levels of fibrinogen, antiplasmin, and plasminogen activation inhibitor (in the $\alpha$-2-globulin fraction of plasma), who suffered repeated episodes of vascular thromboses. Some patients with myocardial infarction and myocardial ischemia (suspected thromboembolic disorders) and cerebral vascular thrombosis have demonstrated increased inhibitors of plasminogen activators and plasmin [29]. Ambrus et al. [1] found decreased plasminogen levels and increased antifibrinolysin activity in premature infants 
and hypothesized that deficient fibrinolysis allows the formation of the fibrin hyaline membrane in neonatal respiratory distress syndrome.

A possible mechanism by which plasma fibrinolytic abnormalities may result in thrombosis was suggested by Fearnley [7]. The hemostatic or occlusive clot is normally protected from fibrinolysis since the interruption of the circulation prevents delivery of plasminogen and fibrinolytic activators. The mural or nonocclusive clot, however, is lysed with the aid of plasminogen and activators from the circulation flowing over the clot. In the presence of decreased plasminogen and increased antiplasmins this protective mechanism may be lacking so that insignificant mural thrombi at the site of local vascular injury may propagate and produce clinically recognized thromboembolic disease.

\section{Summary}

Patients with idiopathic nephrotic syndrome and nephrotic syndrome secondary to chronic renal disease have strikingly increased levels of the antiplasmin $\alpha$-2macroglobulin as measured by an immunological radial diffusion technique. $\alpha$-2-Macroglobulin levels were directly related to the antifibrinolysin activity of the serum. Patients with idiopathic nephrotic syndrome in remission had persistently elevated levels of $\alpha-2$ macroglobulin and antifibrinolysin activity. Patients with idiopathic nephrotic syndrome in exacerbation also had low levels of plasminogen, related to the degree of hypoalbuminemia. Lesser elevation of $\alpha-2$ macroglobulin and normal plasminogen levels were found in other patients with chronic renal disease without the nephrotic syndrome. Three nephrotic patients with thromboembolic episodes had low albumin and plasminogen levels and high $\alpha$-2-macroglobulin or antifibrinolysin levels; six other patients had similar fibrinolytic abnormalities but did not have recognized thromboembolism. Nephrotic patients with low plasminogen and high antiplasmin activity may have a thrombotic tendency because of sluggish fibrinolysis.

\section{References and Notes}

1. Ambrus, C. M., Weinstraub, D. H., Dunphy, D., Dowd, J. E., Pickren, J. W., Niswander, K. R., and Ambrus, J. L.: Studies on hyaline membrane disease. I. The fibrinolytic system in pathogenesis and therapy. Pediatrics, 32: 10 (1963).

2. Borrero, J., Todd, M. E., AND Becker, E. L.: Serum coagulation factors in renal disease (Abstract). J. Clin. Invest., 45: 989 (1966)

3. Copley, A. L., Niewiarowski, S., and Marechal, J.: A micromethod of euglobulin fibrinolysis in plasma of human sub- jects and small laboratory animals. J. Lab. Clin. Med., 53: 468 (1959).

4. Dossetor, J. B., Butelius, J. R., and Kendall, A. G.: The thromboembolic potential of the nephrotic syndrome (Abstract). Int. Congr. Nephrol., p. 184, September 25-30, 1966, Washington, D. C.

5. Edward, N., Young, D. P.-G., and Macleod, M.: Fibrinolytic activity in plasma and urine in chronic renal disease. J. Clin. Pathol., 17: 365 (1964).

6. Ellis, B. C., AND StRANSKY, A.: A quick and accurate method for the determination of fibrinogen in plasma. J. Lab. Clin. Med., 58: 477 (1961).

7. Fearnlex, G. R.: Physiology and pharmacology of fibrinolysis. Brit. Med. Bull., 20: 185 (1964).

8. GANRot, P. O., AND Scherstern, B.: Serum alpha-2-macroglobulin concentration and its variation with age and sex. Clin. Chim. Acta, 15: 113 (1967).

9. Goldbloom, R. B., Hillman, D. A., and Santulli, T. V.: Arterial thrombosis following femoral venipuncture in edematous nephrotic children. Pediatrics, 40: 450 (1967).

10. Guest, M. M., Byrne, M. D., Arnold, G. W., AND SeEgers, W. H.: A study of antifibrinolysin activity in the plasmas of various animal species. J. Clin. Invest., 27: 793 (1948).

11. Guest, M. M., Byrne, M. D., ARnold, G. W., and SeEgers, W. H.: A study of the antifibrinolysin activity in human plasmas during pathological states. J. Clin. Invest., 27: 785 (1948).

12. JacoBsson, K.: Studies on the trypsin and plasmin inhibitors in human blood serum. Scand. J. Clin. Lab. Invest., Suppl. 14: 57 (1954)

13. James, K., Taylor, F. B., JR., and Fudenberg, H. H.: The effect of alpha-2-macroglobulin in human serum on trypsin, plasmin, and thrombin activities. Biochim. Biophys. Acta, 133: 374 (1967).

14. Kluthe, R., Hagemann, U., and Kleine, N.: The turnover of alpha-2-macroglobulin in the nephrotic syndrome. Vox Sang., 12: 3 (1967).

15. Lieberman, E., Heuser, E., Gilchrist, G. S., Donnell, G. N., And Landing, B. H.: Thrombosis, nephrosis, and corticosteroid therapy. J. Pediat., 73: 320 (1968).

16. Lohmann, R. C., Kendall, A. G., Dossetor, J. B., And GaULT, M. H.: The fibrinolytic system in the nephrotic syndrome (Abstract). Clin. Res., 17: 333 (1969).

17. Mancini, G., Carbonara, O., and Heremans, J. F.: Immunochemical quantitation of antigens by simple radial immunodiffusion. Immunochemistry, 2: 235 (1965).

18. NAEYE, R. L.: Thrombotic disorders with increased levels of antiplasmin and antiplasminogen. New Engl. J. Med., 265: 867 (1961).

19. Nilehn, J. E., AND Ganrot, P. O.: Plasmin, plasmin inhibitors and degradation products of fibrinogen in human serum during and after intravenous infusion of streptokinase. Scand. J. Clin. Lab. Invest., 20: 113 (1967).

20. Nilsson, I. M., Krook, H., Sterndy, N. H., and Soderstrom, N.: Severe thrombotic disease in a young man with bone marrow and skeletal changes and with a high content of an inhibitor in the fibrinolytic system. Acta Med. Scand., 169: 323 (1961).

21. Pechet, L.: Fibrinolysis. New Engl. J. Med., 273: 967 (1965).

22. Peterkofsky, A., Levin, L., and Brown, R. K.: Quantitative estimation of antigens by complement fixation. Studies on the heat-labile alpha-2-glycoprotein. J. Immunol., 76: 237 (1956). 
23. Rabiner, S. F., Goldfine, I. D., Hart, A., Summaria, L., and Robrins, K. C.: Radioimmunoassay of human plasminogen and plasmin. J. Lab. Clin. Med., 74: 265 (1969).

24. Steinbuch, M., Quentin, M., ANd Pejaudier, L. Specific technique for the isolation of human alpha-2-macroglobulin. Nature, 205: 1227 (1965)

25. Steines, W. J., AND Mert, J. W.: The elevation of alpha-2macroglobulin and trypsin-binding activity in nephrosis. J. Lab. Clin. Med., 67: 559 (1966).

26. Strefim, E. R.: Unpublished observations (1969).

27. Strehm, E. R., and Trygstad, C. W.: Split products of fibrin in human renal disease. Amer. J. Med., 46: 774 (1969).

28. Swarm, W. R.: Plasminogen assay. Clin. Chem., 14: 262 (1968).

29. Tsitouris, G., Stathopoulou, R., and Tseurenis, I.: Serum inhibition of plasmin and plasminogen activation in thrombotic diseases. J. Atheroscler. Res., 7: 425 (1967).

30. Dr. Charles Reed of the Department of Medicine provided the antiserum to $\alpha$-1-antitrypsin.

31. Plasminogen, Kabi, Stockholm.

32. One standard deviation.
33. Fibrinogen bovine fraction I, Nutritional Biochemicals Corporation, Cleveland, $\mathrm{O}$.

34. Fibrinolysin, bovine, $83 \mathrm{mg} / \mathrm{ml}$, generously provided by $\mathrm{Dr}$. R. E. Maxwell, Parke Davis \& Company.

35. Behringwerke, A. G., Lot DN 166; Certified Blood Donor Service, Inc., Woodbury, N. Y.

36. Rivanol, Aldrich Chemical Company, Inc., Milwaukee, Wis.

37. We thank Miss Linda Kuplic, B.S., for skilled assistance through many phases of this investigation.

38. Supported by Public Health Service Research Grant no. AI-07286 and a Research Career Development Award to E. R. S. from the National Institutes of Allergy and Infectious Diseases. E. R. S. is a John and Mary R. Markle Scholar in Academic Medicine.

39. Dr. J. I. Scheinman's present address is: Department of Pediatrics, William Beaumont General Hospital, E1 Paso, Tex. 79920.

40. Requests for reprints should be sent to: E. Richard Stiehm, M.D., Department of Pediatrics, UCLA Center for the Health Sciences, Los Angeles, Calif. 90024 (USA).

41. Accepted for publication July 15, 1970. 